La interpretación originalista de la Constitución según Antonin Scalia. ¿Es posible en el Derecho Continental?

\author{
Fernando Liendo Tagle *
}

En el presente artículo, el Dr. Fernando Liendo realiza un análisis sobre la interpretación originalista de la Constitución, exponiendo las notas centrales y cómo reconstruye las intenciones del pasado y las traduce a épocas distintas. El autor expone también al adversario teórico denominado Living Constitution y, en base a los elementos establecidos y evidencias aportadas, razona sobre la posibilidad de aplicarse el originalismo a un sistema de Derecho Continental europeo o latinoamericano, como un método interpretativo adicional que puede ser empleado por los tribunales cuando apunten a consolidar un 'estado normativo' que juzguen legítimo conservar.

Abogado por la Pontificia Universidad Católica del Perú. Miembro colaborador de Grupo Peruano de Historia del Derecho y la Justicia del Instituto Riva-Agüero. Actualmente cursa el Máster en Derecho Público en la Universidad Carlos III de Madrid. 
La interpretación originalista de la Constitución según

Antonin Scalia. ¿Es posible en el Derecho Continental?

GigORSETI

\section{La interpretación originalista de la Constitución según Antonin Scalia. ¿Es posible en el Derecho Continental?}

\section{Introducción}

En el contexto de las teorías de la interpretación jurídica, existe un punto de vista que propone centralizar y demarcar la misma, si bien en principio para la interpretación constitucional pero no limitada a esta, en torno a los entendimientos originales de los que redactaron las disposiciones o textos a interpretar. Esta aproximación, se argumenta, sería la más respetuosa de la división de poderes, proporcionaría una base teórica más clara y estable para la interpretación, establecería un propósito compartible por los intérpretes, reforzaría la vinculación y lealtad a la Constitución y sería mejor legitimada en términos democráticos. Esta es el originalismo y su genealogía más clara, tal como se entiende, ha sido desarrollado en el common law en su versión norteamericana.

El propósito de este ensayo consiste en examinar los presupuestos de la misma y razonar sobre la plausibilidad teórica y práctica de su aplicación en los ordenamientos jurídicos europeo-continentales y latinoamericanos. Este trabajo se divide en tres secciones. En la primera hacemos una descripción muy sintética del originalismo tal como lo entiende el juez asociado de la Corte Suprema estadounidense Antonin Scalia, exponiendo las notas centrales y cómo la misma ha encontrado aplicaciones concretas en algunas sentencias de la U.S. Supreme Court, para después precisar los presupuestos teóricos sobre los que se asienta la interpretación originalista, en particular, la posibilidad de reconstruir las intenciones del pasado y traducirlas a épocas distintas a cuando fueron expresadas. En la segunda, resumimos el adversario teórico del originalismo denominado Living Constitution especialmente en los términos propuestos por el profesor David Strauss en su libro con el mismo título. En la tercera, en base a los elementos establecidos y evidencias aportadas, razonamos sobre la posibilidad de aplicarse a un sistema de Derecho Continental europeo o latinoamericano.

En resumen, sostendremos la posición según la cual la interpretación originalista es de facto y de iure empleada por los Tribunales de Derecho Continental. Sin embargo, su empleo sería básicamente discrecional y no podría constituir un método predominante o menos privativo de la interpretación constitucional. Esta posibilidad, sin embargo, no depende de las características primarias que tiene el originalismo en los ordenamientos de 
La interpretación originalista de la

Constitución según Antonin Scalia. ¿Es

posible en el Derecho Continental?

common law, explicadas por singularidades históricas y conceptuales, sino que se puede configurar de conformidad con las tradiciones e identidades constitucionales de cada ordenamiento de inspiración continental. En tal sentido, la interpretación originalista subsistiría como un recurso o método interpretativo adicional que puede ser empleado por los tribunales cuando apunten a afianzar o consolidar un 'estado normativo' que juzguen legítimo conservar. La aproximación originalista, sin embargo, tendría limitaciones epistemológicas que reducirían su aplicabilidad, siendo en todo caso, un punto incontrolable determinar cuándo un tribunal debe optar por una interpretación originalista o, por el contrario, una abierta y dirigida al cambio normativo.

\section{La aproximación originalista del juez Antonin Scalia en pocas palabras}

Empleamos una descripción básica en estos términos: "La idea central del originalismo consiste en que cuando nosotros damos significados a las palabras de la Constitución, deberíamos usar los significados que las personas que adoptaron esas disposiciones constitucionales le habrían asignado ${ }^{\prime 1}$. Planteado en estos términos, el originalismo parece semejante a un método de interpretación familiar y antiguo para los juristas de Derecho Continental como lo sería el de 'descubrir la voluntad del legislador', la 'interpretación histórica', o el 'argumento psicológico' -a veces usando de forma indistinta los términosal momento de adscribir sentido a los textos a interpretar. Esto explica el proceder común de acudir a 'trabajos preparatorios', dictámenes oficiales o 'exposiciones de motivos' de la legislación, a fin de sostener las propuestas de interpretación y apoyar la argumentación jurídica del intérprete. ${ }^{2}$

1 Strauss, David, The Living Constitution, Oxford University Press, 2010, p. 139.

2 Tomemos como ejemplo de la influencia de tal forma de pensar, una posición clásica de un autor de Derecho Privado como WINDSCHEID respecto a cómo concebía la interpretación jurídica y la aspiración de 'determinar con certeza el pensamiento auténtico del legislador', y que puede ser epítome de toda una mentalidad asentada en nuestra tradición jurídica. Textualmente: «Interpretación es la explicación del contenido del derecho. [...] Las leyes son preceptos jurídicos formulados por medio de palabras, y ahí se propone la pregunta de a qué sentido ha vinculado el legislador las palabras que empleó. [...] Según se destacó atrás, lo primero que tiene que hacer la interpretación es explicar el sentido al cual el legislador vinculó las palabras por él empleadas. Presupuesto para ello es la explicación de las propias palabras que usó el legislador. [...] Si este medio tampoco tiene éxito, el intérprete no tiene entonces instrucciones generales que seguir como no sea tratar a todo trance de colocarse a plenitud en la mente del legislador, para así determinar el sentido que este le dio en concreto a las palabras que empleó. [...] Puede ocurrir, y de hecho ocurre frecuentemente que el legislador no haya precisado a cabalidad su pensamiento, porque se adhirió a una forma de expresión que no correspondía exactamente al contenido verdadero de aquel. Es esta la tarea más elevada y noble de la interpretación; en tales casos se acude en ayuda del legislador para establecer y hacer valer su propia voluntad frente a lo expresado, sin que

FORSETI

Número 1

194 
La interpretación originalista de la Constitución según Antonin Scalia. ¿Es posible en el Derecho Continental?

Ambas aproximaciones interpretativas, ¿son lo mismo o tienen sus propios matices? A nuestro juicio, hay diferencias. A nuestro juicio, el originalismo está en directa relación con la interpretación de las disposiciones contenidas en la Constitución norteamericana y sus enmiendas, y sobre todo vinculada a los matices de la tradición jurídica en el que se forjó.

La teoría de la interpretación originalista tiene múltiples desarrollos. De hecho, el debate sobre la misma es una de las áreas de investigación en Derecho Constitucional más prolíficas y de plena actualidad. Dentro del originalismo existe una diversidad de autores y perspectivas, entre los que podemos nombrar a Robert Bork, Clarence Thomas, Hugo Black, y por supuesto, Antonin Scalia. Ahora bien, dentro del originalismo no existe una posición uniforme en cuanto a los límites y ámbito del mismo. Así, existen originalistas moderados, estrictos, originalistas timoratos, entre otros. La idea común, desde luego, es la previamente señalada. ${ }^{3}$

Dentro de esta diversidad, resumiremos los postulados esenciales de uno de los originalistas más prominentes, no sólo por su relevancia académica sino principalmente por su obra jurisprudencial, como el justice Antonin Scalia. El procedimiento a seguir será sintetizar los postulados generales de su posición expuestos en dos textos clásicos que

pueda afirmarse que entonces la interpretación rebase sus atribuciones, toda vez que se desempeña íntegramente dentro del sentido del legislador; simplemente expresa lo que habría expresado éste, en forma cierta y consciente, caso de haber sido más cuidadoso sobre un punto que no aprehendió a cabalidad. Así se reiteran los límites a la interpretación que, tales como fueron señalados antes: Si se quiere determinar con certeza el pensamiento autentico del legislador, debe expresarse como derecho fundado en la interpretación tan solo el que se reconozca en la declaración legislativa y cuando no se pueda encontrar ninguna expresión completa correspondiente al pensamiento del legislador, de todos modos ha de llegarse a una expresión en general, y así también se establece que la actividad principal, si no única, de la interpretación, en la complementación o la restricción de la ley. WINDSCHEID, BERNHARD. Tratado de Derecho Civil Alemán: Derecho de Pandectas. Bogotá: Universidad Externado de Colombia. Tomo I. Vol. I. 1987. pp. 77, 78, 81, 83. Por otro lado, algunos ordenamientos que tienen positivizadas las prescripciones sobre la interpretación del Derecho en general, con las críticas y problemas que ello puede conllevar, contemplan de alguna forma este método de interpretación. Solo por recordar el artículo $3^{\circ}$ del Código Civil español sobre reglas de aplicación de las normas jurídicas. «Las normas se interpretarán según el sentido propio de sus palabras, en relación con el contexto, los antecedentes históricos y legislativos y la realidad social del tiempo en que han de ser aplicadas, atendiendo fundamentalmente al espíritu y finalidad de aquellas».

Para un panorama completo del originalismo, desde la filosofía del Derecho, está publicado en español: De Lora del Toro, Pablo, La interpretación originalista de la Constitución, Centro de Estudios Políticos y Constitucionales BOE, Madrid, 1998, pp. 343. 
La interpretación originalista de la

Constitución según Antonin Scalia. ¿Es

posible en el Derecho Continental?

bien pueden ser dos de los ensayos más relevantes en esta escuela: Originalism: The Lesser Evil ${ }^{4}$ y el Common-Law Courts in a Civil-Law System: The Role of United States Federal Courts in Interpreting the Constitution and Laws. ${ }^{5}$ Una vez expuesta la teoría, examinaremos una aplicación judicial concreta en el caso District of Columbia v. Heller donde podremos evidenciar cómo es que funciona el originalismo en la práctica.

a. Ante todo, la posición interpretativa de Scalia se funda, antes que en una inmediata apelación a las intenciones originales de los autores de las disposiciones, en un análisis preferente de los textos. Este textualismo es pues el punto de partida desde el cual la interpretación puede empezar a desarrollarse. Así:

"Lo que busco en la Constitución es precisamente lo que busco en una Ley [Statue]: el significado original del texto, no lo que el redactor original se propuso [...] Consultaré los escritos de algunos hombres que resultaron ser los Framers -los escritos de Hamilton y Madison en el Federalista, por ejemplo-. Lo hago, sin embargo, no porque ellos fueron los autores y por tanto su intención es autoridad y debe ser el Derecho; sino más bien porque sus escritos, como aquellos de otras personas inteligentes e informadas de su tiempo, hacen visible cómo el texto de la Constitución fue originalmente entendido". ${ }^{6}$

b. El problema que encuentra con otros modelos interpretativos es:

"El principal defecto teorético del no-originalismo, en mi opinión, es su incompatibilidad con el principio mismo que legitima la judicial review de constitucionalidad [...] Central para este análisis, me parece, es la percepción de que la Constitución, aunque tiene un efecto superior que otras leyes, es en su naturaleza un tipo de 'Derecho' que es la ocupación de los tribunales un estatuto que tiene un significado fijado determinable a través de los

4 Scalia, Antonin, Originalism: The Lesser Evil, University of Cincinnati Law Review Vol. 57, 1988-1989, pp. 849-865.

5 Scalia, Antonin, "Common-Law Courts in a Civil-Law System: The Role of United States Federal Courts in Interpreting the Constitution and Laws" A Matter of Interpretation: Federal Courts and the Law, Amy Gutmann (Ed.) Princeton University Press, New York, 1997. Otro texto relevante, no tanto desde el originalismo sino para comprender el formalismo jurídico de Scalia es: Scalia, Antonin, "The Rule of Law as a Law of Rules", The University of Chicago Law Review No. 56, 1989.

Ibid., pp.112. [Nota: Todos los textos citados han sido traducidos del inglés por el autor, salvo indicación en contrario. En algunos extremos hemos optado por conservar algunos términos en lengua inglesa por la precisión que tienen en lengua original y que se diluye en la traducción: por ejemplo, Bill of Rights, Statue, Framer, entre otros.] 
mecanismos usuales, que son familiares a los formados en Derecho-. Si la Constitución no fuese tal clase de 'Derecho', sino una invitación nueva a aplicar los valores sociales actuales, ¿qué razón existiría para pensar que tal invitación fue dirigida a los tribunales más bien que a la legislatura? Bastante lo contrario, la legislatura parece ser un expositor mucho más apropiado de los valores sociales, y su determinación en torno a que una Ley es compatible con la Constitución debería, como en Inglaterra, prevalecer. ${ }^{\prime \prime}$

c. Las razones de fondo para optar por tal aproximación descansarían, entonces, en la legitimidad teórica y democrática de la misma. Así: "Tomo seriamente la necesidad de legitimación teórica, e incluso si uno supone (como muchos no-originalistas ni se toman la molestia de hacerlo) que la Constitución fue originalmente adoptada con el propósito de expresar valores evolutivos antes que permanentes, como se discutió antes, no veo fundamento para creer que la supervisión de tal evolución habría sido puesta a cargo de los tribunales. Incluso en un nivel teorético más general, el originalismo parece ser más compatible con la naturaleza y el propósito de una Constitución en un sistema democrático. Una sociedad democrática no necesita, por lo general, garantías constitucionales para asegurar que sus leyes reflejen los 'valores actuales'. Las elecciones se ocupan de eso bastante bien. El propósito de las garantías constitucionales -y en particular aquellas garantías constitucionales de derechos individuales que son el centro de esta controversia- es precisamente impedir al Derecho reflejar ciertos cambios en valores originales que la sociedad al adoptar la Constitución considera fundamentalmente como indeseables. O, más precisamente, requerir a la sociedad dedicar al asunto una larga y severa consideración, requerida para una enmienda constitucional antes de que estos valores particulares puedan ser dejados de lado. ${ }^{\prime 8}$

d. Sobre el método mismo de la interpretación originalista, el propio Scalia reconoce las dificultades de ser seguido y aplicado. Así: " [...] es verdad que es frecuente y extremadamente difícil explorar el entendimiento original de un texto antiguo. Apropiadamente efectuada, la tarea requiere la consideración de una enorme masa de material -en el caso de la Constitución y sus Enmiendas, por ejemplo, para mencionar un solo elemento: los registros de los debates de ratificación en todos los Estados-. Incluso más allá de esto, requiere una evaluación de la confiabilidad 
de tal material -muchos de los reportes de estos debates de ratificación, por ejemplo, son considerados no fiables-. Y en adición todavía, requiere sumergirse uno mismo en la atmósfera política e intelectual del tiempo, de alguna manera poniendo fuera de nuestra mente conocimientos que tenemos, los cuales no tenían en una época previa, y adoptando convicciones, actitudes, filosofía, prejuicios y lealtades que no son aquellos de nuestros días. Es, en resumen, una tarea a veces mejor efectuada por el historiador que el jurista". 9 Sin embargo: "Los defectos prácticos del originalismo, por otra parte, aunque suficientemente genuinos, me parecen menos severos. Aunque en efecto sea irreal tener una confianza sustancial que los jueces y abogados encontrarán la respuesta histórica correcta para cuestiones refinadas en torno al propósito original del contenido preciso del 'Poder ejecutivo', para la mayoría de cuestiones la respuesta es clara". ${ }^{10}$

e. A pesar de las limitaciones y dificultades epistemológicas que este modelo propone, Scalia considera que es un fundamento mucho más claro y seguro que el presentado por otros tipos de interpretación, que proponen abandonar el entendimiento original como canon interpretativo básico. Otros modelos no tienen con qué reemplazarlo $o$, en todo caso, el consenso sobre qué fundamento se debería emplear es altamente complicado. Así: "el defecto central del nooriginalismo es irreparable: la imposibilidad de lograr algún consenso sobre, precisamente, lo que va a reemplazar el significado original una vez que es abandonado". ${ }^{11}$ Este defecto es incluso compartido por los originalistas en tanto no siempre habrá consenso entre ellos sobre cuál es el significado original del texto, pero al menos subyacerá un punto de acuerdo fundamental sobre lo que se busca. Así:

"Hay bastante espacio para el desacuerdo respecto a cuál fue el significado original, e incluso mucho más en torno a cómo ese significado original se aplica ante una situación [un fenómeno nuevo y no previsto] ante la corte. Pero el originalista al menos sabe lo que está buscando: el significado original del texto". ${ }^{12}$

$9 \quad$ Scalia, Antonin, Originalism: The Lesser Evil.., pp. 856-857.

10 Scalia, Antonin, Originalism: The Lesser Evil..., p. 863.

11 Scalia, Antonin, Originalism: The Lesser Evil..., pp. 862-863.

12 Scalia, Antonin, "Common-Law Courts in...", pp.118. Se plantea así: "How, for example, does the First Amendment guarantee of "the freedom of speech" apply to new technologies that did not exist when the guarantee was created - to sound trucks, or to government-licensed over-the-air television? In such new fields the Court must follow the trajectory of the First Amendment, so to speak, to determine what it requires-and assuredly that enterprise is not entirely cut-and-dried, but requires the exercise of judgment". 
La interpretación originalista de la Constitución según Antonin Scalia. ¿Es posible en el Derecho Continental?

f. Este modelo interpretativo se contrapone con aquél basado en lecturas morales, evolutivas o ius-filosóficas de la Constitución, los cuales constituirían una base mucho más incierta e insegura para responder preguntas constitucionales en tanto la clave para determinar el cambio sería incognoscible, y probablemente las soluciones serían menos aptas para producir resultados aceptables para todos. Así los jueces no interpretarían erróneamente o confundirían sus propias preferencias con lo que es o debería ser el Derecho. ${ }^{13}$ Para Scalia, las aproximaciones interpretativas diversas, una vez que salimos del texto y la evidencia histórica, serían una aproximación más bien filosófica sobre cuáles deben ser los valores fundamentales que deben aplicar los tribunales, sobre todo en los casos en que se sostiene que los tribunales deberían 'aplicar los valores fundamentales actuales de la sociedad' y dejar a un lado los predominantes del pasado. Scalia se pregunta: "

Scalia, Antonin, Originalism: The Lesser Evil..., pp.853-854. En su apoyo sostiene contra los que rechazan el significado original y abogan por las lecturas morales o evolutivas de la Constitución: "Those who have not delved into the scholarly writing on constitutional law for several years may be unaware of the explicitness with which many prominent and respected commentators reject the original meaning of the Constitution as an authoritative guide. Harvard Professor Laurence $\mathrm{H}$. Tribe, for example, while generally conducting is constitutional analysis under the rubric of the open ended textual provisions such as the Ninth Amendment, does not believe that the originally understood content of those provisions has much to do with how they are to be applied today. The Constitution, he has written, "invites us, and our judges, to expand on the freedoms that are uniquely our heritage,"' and "invites a collaborative inquiry, involving both the Court and the country, into the contemporary content of freedom, fairness, and fraternity."' Stanford Dean Paul Brest, having (in his own words) "abandoned both consent and fidelity to the text and original understanding as the touchstones of constitutional decision making," concludes that "the practice of constitutional decision making should enforce those, but only those, values that are fundamental to our society." While Brest believes that the "text," "original understanding," "custom," "social practices," "conventional morality," and "precedent" all strongly inform the determination of those values, the conclusions drawn from all these sources are "defeasible in the light of changing public values."' Yale Professor Owen Fiss asserts that, whatever the Constitution might originally have meant, the courts should give "concrete meaning and application" to those values that "give our society an identity and inner coherence [and] its distinctive public morality." Oxford Professor (and expatriate American) Ronald Dworkin calls for "a fusion of constitutional law and moral theory." Harvard Professor Richard Parker urges, somewhat more specifically, that constitutional law "take seriously and work from (while no doubt revising) the classical conception of a republic, including its elements of relative equality, mobilization of citizenry, and civic virtue." More specifically still, New York University Professor David Richards suggests that it would be desirable for the courts' constitutional decisions to follow the contractarian moral theory set forth in Professor John Rawls' treatise, A Theory of Justice. And I could go on". 
La interpretación originalista de la

Constitución según Antonin Scalia. ¿Es

posible en el Derecho Continental?

¿Están los 'valores fundamentales', que reemplazan el significado original, derivados de la filosofía de Platón, Hume, Locke, o de Rawls, o quizá de la última encuesta del Gallup?". ${ }^{14} \mathrm{Y}$ en tal sentido, el consenso sobre lo mismo es muy difícil. No existiría propiamente un principio rector o guía de esta evolución, y menos un acuerdo o la posibilidad de llegar a un acuerdo sobre esto.

g. Finalmente, Scalia menciona que no es cierto que mantener una aproximación originalista implique necesariamente una reducción de derechos y que, por el contrario, las posiciones evolutivas garanticen una expansión de libertades y derechos. Así: "[...] el registro de la historia refuta la proposición de que la Constitución viva acrecentará los derechos individuales". 15 "[...] Nuestra sociedad moderna es indudablemente no tan entusiasta sobre libertades económicas como lo fueron los hombres y mujeres de 1789; pero no deberíamos engañarnos a nosotros mismos al creer que porque nos gusta el resultado el resultado no representa una contradicción de la libertad. El no-originalismo, en otras palabras es una calle de dos sentidos que conduce el tráfico en ambas vías, para y desde los derechos individuales. [...] esto sólo muestra que los Framers acertaron cuando temieron que alguna (en su perspectiva, carente de orientación) futura generación pueda desear abandonar las libertades que ellos consideraron esenciales, por lo que buscaron proteger estas libertades en un Bill of Rights. Nos puede agradar el acortamiento de los derechos de propiedad y agradar la eliminación del derecho de portar armas; pero no pretendamos que esto no es una reducción de derechos". ${ }^{16}$ El resultado de las tesis no originalistas no siempre será una expansión de los derechos mientras el originalismo implique siempre una restricción de los mismos.

En conclusión, vemos cómo Scalia nos propone un enfoque o aproximación interpretativa basada en evidencias textuales o históricas para encontrar las soluciones acertadas a las preguntas constitucionales. Desde luego, el propio originalismo es consciente de las limitaciones epistemológicas y prácticas que existen al intentar descubrir este entendimiento o propósito original: la historia legislativa es muchas veces imprecisa y confusa, en múltiples ocasiones no puede inferirse una clara voluntad de los registros o documentación referida a los orígenes de una legislación, entre otras. De ahí que el punto de partida sean los textos, antes de que las intenciones del legislador se deba enfocar la atención en el significado original de los textos redactados y aprobados por él, dentro del ámbito de significado de las palabras, y de acuerdo al contexto y a la evidencia disponible a fin de construir una interpretación razonable del Derecho.

14 Scalia, Antonin, Originalism: The Lesser Evil..., p. 855.

15 Scalia, Antonin, Originalism: The Lesser Evil..., p. 856.

16 Scalia, Antonin, "Common-Law Courts in...", p. 116.

FORSETI

Número 1

2015

200 
La interpretación originalista de la Constitución según

Antonin Scalia. ¿Es posible en el Derecho Continental?

\subsection{Un caso de interpretación originalista: District of Columbia v. Heller.}

A fin de ejemplificar el sentido y tener una comprensión más exacta de este modelo interpretativo, tomamos un caso concreto donde fue aplicado y tuvo un rol estelar. Así, en District of Columbia, Et Al., v. Dick Anthony Heller 554 U. S. 570 (2008), el justice Scalia presentó la opinión mayoritaria (5-4) de la Corte al juzgar si una prohibición del Distrito de Columbia de posesión en el hogar de revólveres o armas de fuego susceptibles de funcionar violaba la Segunda Enmienda de la Constitución. Con un áspero disenso de los justices John Paul Stevens y Stephen Breyer, que abordaron fuentes históricas y llegaron a una conclusión diferente, la posición originalista prevaleció en los siguientes términos.

Estaba en cuestión el alcance e interpretación de la Segunda Enmienda según la cual: " $A$ well regulated Militia, being necessary to the security of a free State, the right of the people to keep and bear Arms, shall not be infringed' ['Siendo necesaria una Milicia bien ordenada para la seguridad de un Estado Libre, no se violará el derecho del pueblo a poseer y portar armas']. Para Scalia el primer paso es realizar un 'análisis textual ${ }^{17}$ a fin de determinar el significado de la Segunda Enmienda. Así, procede a definir y precisar el significado de cada uno de los elementos de la proposición; define la cláusula preliminar y la cláusula clave. Procede sintagma por sintagma. Define los términos "Well-Regulated Militia", "Security of a Free State", contenidos en la cláusula preliminar y después los términos "Right of the People"y "Keep and bear Arms", de la cláusula esencial, y enfoca el razonamiento en si el uso de armas está en necesaria conexión con el servicio en una milicia o si puede predicarse la existencia de un derecho independiente de portar armas en una milicia, como se podría inferir también del texto.

Básicamente, después de pasar revista a diccionarios y escritos desde 1773 a la fecha, ${ }^{18}$ arriba a la conclusión de que el significado de estos términos en el Siglo XVIII no es sustancialmente diferente al de hoy día. Y lo más importante:

17 District of Columbia, Et Al., v. Dick Anthony Heller 554 U.S. 570, 2008, p. 5.

18 District of Columbia, Et Al., v. Dick Anthony Heller 554 U.S. 570, 2008, p. 7. Textualmente: "The 18th-century meaning is no different from the meaning today. The 1773 edition of Samuel Johnson's dictionary defined "arms" as "weapons of offence, or armor of defense." Dictionary of the English Language 107 ( $4^{\text {th }}$ Ed.) (Hereinafter Johnson). Timothy Cunningham's important 1771 legal dictionary defined "arms" as "anything that a man wears for his defense, or takes into his hands, or used in wrath to cast at or strike another." A New and Complete Law Dictionary (1771); see also N. Webster, American Dictionary of the English Language (1828) (reprinted 1989) (hereinafter Webster) (similar)".

FORSETI

Número 1

2015

201 
La interpretación originalista de la

Constitución según Antonin Scalia. ¿Es

posible en el Derecho Continental?

"Colocando todos estos elementos textuales juntos, encontramos que ellos garantizan el derecho individual a poseer y portar armas en caso de confrontación. Este significado está confirmado fuertemente por el trasfondo histórico de la Segunda Enmienda. Examinamos esto porque siempre ha sido ampliamente entendido que la Segunda Enmienda, como la Primera y la Cuarta Enmienda, codificaron un derecho pre-existente". ${ }^{19}$

Y apoya esta conclusión revisando también antecedentes históricos relevantes como por ejemplo los Comentarios de Blackstone, el derecho de portar armas como una consecuencia del derecho natural a la 'auto-preservación'..20 También sobre lo sucedido en Inglaterra en la gestación de su Bill of Rights: "La historia muestra que la manera en que los tiranos eliminaron una milicia de todos los hombres capaces, no fue prohibiendo la milicia sino simplemente tomando las armas de las personas, permitiendo a una milicia selecta o al ejército en pie suprimir a sus oponentes políticos. Esto es lo que había ocurrido en Inglaterra que dio lugar a la codificación del derecho a tener armas en el Bill of Rights inglés". ${ }^{21}$ A mayor detalle: "Entre la Restauración y la Revolución Gloriosa, los reyes Stuart, Carlos II y Jacobo II tuvieron éxito al suprimir oponentes políticos al desarmarlos. Esto generó que los ingleses tuvieran la honda preocupación de la concentración de fuerzas militares dirigidas por el Estado y sean recelosos de sus armas. De ahí que obtuvieran la garantía de que los protestantes no serían nunca desarmados. ${ }^{22}$ [...] Este derecho ha sido largamente entendido como el predecesor de nuestra Segunda Enmienda. Claramente un derecho individual, no tenía que ver con el servicio en una milicia". ${ }^{23}$ A mayor abundamiento: "Así, el derecho asegurado en 1689 como el resultado de los abusos de los Stuart fue en el tiempo de la fundación entendido a ser un derecho individual que protegía contra la violencia pública y privada. ${ }^{24} \mathrm{Y}$, por supuesto, lo que los Stuart intentaron hacer con sus enemigos políticos, el rey Jorge III intentó con los colonos en Estados Unidos. En las tumultuosas décadas de 1760 y 1770, la Corona empezó a desarmar a los habitantes de las zonas más rebeldes. Esto provocó reacciones polémicas de los norteamericanos que invocaban sus derechos como ingleses a portar armas", tal como lo documenta textos y artículos de la época (1769), citados también en la sentencia. ${ }^{25}$

19 District of Columbia, Et Al., v. Dick Anthony Heller 554 U.S. 570, 2008, p. 19.

20 District of Columbia, Et Al., v. Dick Anthony Heller 554 U.S. 570, 2008, p. 21.

21 District of Columbia, Et Al., v. Dick Anthony Heller 554 U.S. 570, 2008, p. 25.

22 El texto inglés prescribió: "That the subjects which are Protestants may have arms for their defense suitable to their conditions and as allowed by law." Disponible en: http://www.legislation.gov.uk/aep/WillandMarSess2/1/2/introduction

District of Columbia, Et Al., v. Dick Anthony Heller 554 U.S. 570, 2008, p. 20.

District of Columbia, Et Al., v. Dick Anthony Heller 554 U.S. 570, 2008, p. 21.

District of Columbia, Et Al., v. Dick Anthony Heller 554 U.S. 570, 2008. "A New York article of April 1769 said that "[i]t is a natural right which the people have reserved to themselves,

FORSETI

Número 1

2015

202 
Después de hacer esta reconstrucción histórica, la sentencia examina, en virtud al principio de stare decisis, si alguno de sus precedentes excluye las conclusiones a las que arribaron respecto al significado de la Segunda Enmienda. Y se examina United States v. Cruikshank, 92 U. S. 542, Presser v. Illinois, 116 U. S. 252 (1886), United States v. Miller, 307 U. S. 174 (1939), llegando a la conclusión de que "nada en nuestros precedentes excluye nuestra adopción del entendimiento original de la Segunda Enmienda". ${ }^{26}$ Finalmente, el resultado de la interpretación originalista es que: "La sola enumeración de derechos extrae de las manos de gobierno -incluso del tercer ramo del Gobierno- el poder de decidir en una base de caso-por-caso si realmente vale la pena insistir en tal derecho. Una garantía constitucional sometida a la futura evaluación de los jueces sobre su utilidad, no es una garantía constitucional en absoluto. Los derechos constitucionales están consagrados con el alcance con que las personas que los adoptaron entendieron que debían guardar, sin importar o no si legislaturas futuras o incluso (sí) si los jueces futuros piensen que tal alcance es demasiado amplio". ${ }^{27}$ Respecto a la presunta obsolescencia de tal disposición constitucional, la sentencia afirma:

"Somos conscientes del problema que la violencia de armas de fuego en este país y tomamos seriamente las preocupaciones subrayadas por muchos amici quienes creen que la prohibición de la posesión de armas de fuego es una solución. [...] indudablemente algunos piensan que la Segunda Enmienda está obsoleta en una sociedad donde nuestro ejército es el orgullo de la Nación, donde fuerzas policiales bien entrenadas proporcionan seguridad personal, y donde la violencia de las armas es un serio problema. Esto es tal vez discutible, pero lo que no es discutible es que no es la función de esta Corte declarar la extinción de la Segunda Enmienda". ${ }^{28}$

\subsection{Presupuestos de la interpretación originalista.}

Luego de este breve recorrido -inevitablemente aleatorio y sintético- estamos listos para establecer algunas características básicas sobre la interpretación jurídica que nos propone el originalismo:

confirmed by the Bill of Rights, to keep arms for their own defence." A Journal of the Times: Mar. 17, New York Journal, Supp. 1, Apr. 13, 1769, in Boston Under Military Rule 79 (0. Dickerson ed. 1936); see also, e.g., Shippen, Boston Gazette, Jan. 30, 1769, in 1 The Writings of Samuel Adams 299 (H. Cushing ed. 1968)".

District of Columbia, Et Al., v. Dick Anthony Heller 554 U.S. 570, 2008, p. 53.

District of Columbia, Et Al., v. Dick Anthony Heller 554 U.S. 570, 2008, p. 63.

District of Columbia, Et Al., v. Dick Anthony Heller 554 U.S. 570, 2008, p. 64.

FORSETI

Número 1

2015

203 
a. Aunque sea bastante obvio, el punto de partida son los textos. No son los antecedentes históricos y legislativos per se los que tendrían un sentido definitivo, sino los textos y el significado y alcance de las palabras contenidas en los mismos.

b. En la medida que un análisis textual sea insuficiente para responder a las preguntas planteadas, el intérprete debería acudir a las fuentes que explican los orígenes de la legislación o disposiciones constitucionales interpretadas. En este caso, no se trata propiamente de llegar a establecer una voluntad histórica plenamente reconstruida, sino de descubrir qué significado se otorgó a los textos cuando se convirtieron en Derecho.

c. El presupuesto epistemológico es entonces es posible traducir los significados del pasado al presente, así exista una distancia histórica sumamente amplia, como en el caso de las disposiciones constitucionales norteamericanas de los Siglos XVIII y XIX. Merece la pena detenerse en el término 'traducción' y cómo se aplica a la interpretación jurídica. El Diccionario de la Real Academia nos recuerda que procede del latín 'traducĕre', o 'hacer pasar de un lugar a otro'. ${ }^{29}$ De acuerdo al originalismo, podemos traducir el significado que las provisiones tenían en el pasado, emitidas en el tiempo en que se convirtieron en Derecho, y aplicarlas a un mundo distinto y nuevo como el de nosotros. Hacer esto no sería una simple preferencia interpretativa, sino la forma más genuina de hacer que la Constitución sea lo que tiene que ser: una norma superior que contiene unos derechos, cláusulas y principios que deben ser permanentes antes que susceptibles de cambio por otro Derecho de contenidos diferentes.

d. El originalismo propone que su aproximación tendría una base más segura desde una perspectiva epistemológica. Si una vez superado el análisis textual, persisten los dilemas interpretativos, el originalismo apuesta por recurrir al entendimiento y significado original del texto a interpretar, recurriendo para ello a la evidencia histórica disponible que ilumine el sentido de las palabras. Este punto de vista, entonces, se distancia de las posiciones consistentes en razonamientos morales o filosóficos sobre el sentido de los principios contenidos en las Constituciones. La distancia de posiciones como las de Dworkin es palmaria.

e. El problema con las lecturas morales, según este punto de vista, es que dependerían de la adscripción a una filosofía determinada, y una vez en ese ámbito

Las otras acepciones del Diccionario son igual de útiles e iluminan esta idea: (Del lat. traducěre, hacer pasar de un lugar a otro). 1. tr. Expresar en una lengua lo que está escrito o se ha expresado antes en otra. / 2. tr. Convertir, mudar, trocar. / 3. tr. Explicar, interpretar. 
es difícil precisar si el intérprete se decantara, por ejemplo, por la filosofía práctica de Aristóteles, Kant, Hume, o Mill. El problema con esta opción, como lo entienden los originalistas, consiste en que: i) es imposible lograr un consenso entre los intérpretes sobre qué filosofía moral y jurídica aplicar, en tanto serían términos inconmensurables al no existir una jerarquía entre ellos; ii) el Estado de Derecho se vaciaría de contenido, pues al permitir eso ya no se contaría con un 'gobierno de las leyes', sino que al final sería un grupo de jueces los que imponen sus preferencias frente a las reglas y provisiones constitucionales democráticamente aprobadas y que están dirigidas a limitar la legislación y restringir la actuación pública ordinaria.

f. El originalismo presupone que es posible reconstruir un entendimiento con bastante exactitud. Para ello, procede básicamente como lo haría un historiador: revisa fuentes escritas sobre el proceso legislativo, comprueba su confiabilidad y las confronta con otras evidencias indirectas como diccionarios y escritos de la época, a fin de verificar si el aserto que propone el intérprete tiene un soporte verificable. En tal sentido, el método que sigue es parecido al del historiador: su objeto de verificación no está en el presente sino en el pasado y debe fundarse en fuentes que superen una crítica externa de autenticidad (no emplear una fuente apócrifa) e interna de veracidad o credibilidad, luego de lo cual llegará a una síntesis en base a los elementos encontrados. Desde luego, no es nuestro propósito examinar el estatuto epistemológico de tal saber sino únicamente indicar que es un presupuesto teórico en el que se asienta la interpretación originalista.

g. Finalmente, el originalismo considera que esta examinación minuciosa del texto, la historia del texto, el entendimiento tradicional del texto (para lo cual, siguiendo el common law, acudirá también a los precedentes), es el modelo interpretativo más respetuoso del principio de separación de poderes, el self-restraint, y en suma al Rule of Law. La interpretación originalista es la que mayor deferencia guardaría al Estado de Derecho.

\section{La cara opuesta de la interpretación originalista: The Living Constitution.}

Hemos establecido las notas básicas del planteamiento originalista. Ahora, para presentar la manera de pensar contraria y tener una perspectiva balanceada de las posiciones en conflicto, describimos brevemente los planteamientos de los objetores de la idea de la 
La interpretación originalista de la

Constitución según Antonin Scalia. ¿Es

posible en el Derecho Continental?

interpretación originalista, es decir, los defensores de una 'Constitución Viva'. ${ }^{30}$ A fin de simplificar la exposición, empleamos la propuesta de David Strauss en su libro The Living Constitution.

Para los seguidores de una Constitución viviente, el dilema de la legitimidad teórica de los tribunales para interpretar la Constitución e introducir entendimientos distintos a los previstos por los Framers sobre la misma es básicamente resuelto y superado en la consideración de que esto es lo que, de hecho ya ha sucedido en el desarrollo del Derecho Constitucional, y que existen buenas razones para que esto deba ser así. Quizá la razón más importante que explica tales cambios en el entendimiento de la Constitución, y cómo ésta se pudo adaptar a épocas tan distintas de cuando fue redactada y ratificada, consiste en que la interpretación constitucional ha sido y seguido el camino de la naturaleza del common law. La tesis central se resume en: "Nuestro sistema constitucional, sin darnos cuenta por completo, ha sacado provecho de una antigua fuente de derecho, una que antecede a la Constitución misma por muchos siglos. Este antiguo tipo de derecho es el common law. El common law es un sistema construido no sobre un texto autoritativo fundacional cuasi sagrado, como la Constitución. Más bien, el common law es construido desde precedentes y tradiciones que se acumulan con el paso del tiempo. Estos precedentes dejan espacio para la adaptación y el cambio, pero solo dentro de ciertos límites y solo de maneras que han sido arraigadas en el pasado. Nuestro sistema constitucional -voy a sostener- se ha convertido en un sistema de common law, uno en el cual el precedente y las prácticas pasadas son, en su propio modo, tan importantes como la Constitución escrita de los Estados Unidos misma. Una Constitución de common law es una Constitución Viva". ${ }^{31}$

Se argumenta que, si se siguiera la idea de interpretación originalista, la vida constitucional norteamericana sería irreconocible. Así, Strauss propone como evidencia del error del originalismo los siguientes ejemplos de principios jurídicos actuales que, de seguir el entendimiento original con el que fueron emitidos, no existirían. ${ }^{32}$ La segregación racial en

30 No siendo nuestro objeto de estudio, nos limitamos a enumerar unas notas fundamentales. Naturalmente, existe una diversidad entre estos, tanto del sector académico, autores como Bruce Ackerman o en el judicial, como sería el juez Stephen Breyer.

31 Strauss, David, Op. cit., p.3.

32 Strauss, David, Op. cit., pp. 77-92. La evidencia histórica muestra que la Cláusula de protección igualitaria no fue entendida para evitar prohibir la segregación en colegios públicos (el Congreso que propuso la enmienda segregó colegios en el distrito de Columbia.) El Gobierno sería libre de discriminar a la mujer. Nuevamente en 1868 la Decimocuarta Enmienda no era entendida como invalidante de la discriminación a la mujer. El Gobierno federal podría cometer discriminaciones contra minorías raciales (o contra cualquiera o contra quien quisiera) cuando quisiese, en tanto la enmienda se refiere a los Estados y no al Gobierno Federal. 
las escuelas públicas sería constitucional, bastante legislación federal de medioambiente, trabajo y protección del consumidor sería inconstitucional, el Bill of Rights no sería aplicable a los Estados en tanto que cuando se adoptó solo se aplicó al Gobierno Federal permitiendo que los Estados cometan conductas contrarias al mismo, el alcance de la libertad de expresión sería muy reducido y protegería el otrora delito de blasfemia, la regulación económica de muchos mercados no sería posible en tanto la limitación del Gobierno Federal tenía un entendimiento claramente distinto en 1787 al de hoy en día, la discriminación por razón de sexo o raza sería posible por parte de los estados, entre otros. ${ }^{33}$

La forma en que la Constitución norteamericana pudo sobrevivir tanto tiempo se debe a que aprovechó la tradición del common law para adaptarse a nuevos tiempos. Así, la manera en que esta Constitución de common law se desarrolla es una de las más antiguas formas de derecho consistente en la acumulación y evolución de precedentes, formados por nociones de justicia y buena política. Este common law por el que se desarrolló el Derecho Privado en Inglaterra y que restringió y orientó a los Tribunales es la aproximación que explica lo que el Derecho Constitucional en realidad es. Así: "Si uno piensa que la Constitución es solamente el documento que está bajo las vitrinas del archivo nacional, uno no empezará a entender el derecho constitucional norteamericano". ${ }^{34}$ Para Strauss, tener una Constitución de common law no genera que los tribunales puedan manipular o hacer de ella lo que quieran. Es una forma de entender el Derecho antes que como la orden de un jefe soberano, como un conjunto de costumbres que son declaradas por los tribunales y esta acumulación de precedentes genera una evolución del Derecho. $Y$ se basa en una actitud de humildad, de sentido práctico para buscar la solución de mejores resultados, y de respeto por la sabiduría acumulada en el pasado. El common law restringe la discrecionalidad al exigir que los jueces examinen y sigan los precedentes, reduciendo el ámbito de su decisión. ${ }^{35}$

Finalmente el originalismo no puede responder a la pregunta de Thomas Jefferson de por qué una generación debe seguir las decisiones adoptadas hace cientos de años por personas que ya no están vivas. ${ }^{36}$ Esto se respondería en el sentido de que las lecciones que ha dejado la historia de lidiar con problemas fundamentales y que implicaron que las nuevas generaciones adopten decisiones trascendentales para su autogobierno, no han sido propiamente incorporadas en el documento escrito sino que encontraron otras formas

33 Strauss, David, Op. cit., pp. 12-18.

34 Strauss, David, Op. cit., pp. 35-36.

35 Strauss, David, Op. cit., pp. 36-46.

36 Strauss, David, Op. cit., p. 18.

FORSETI

Número 1

2015

207 
de evolución. Así: "Están más bien materializadas en los casos decididos en la Corte Suprema, así como en las tradiciones y entendimientos que se han desarrollado fuera de las Cortes. Estos precedentes, tradiciones y entendimientos forman una parte indispensable de lo que puede ser llamada nuestra constitución con ' $c$ ' minúscula: la constitución como en efecto opera, en la práctica. Esta constitución con ' $c$ ' minúscula es nuestra Constitución viva". ${ }^{37}$ Para Strauss, solo una Constitución del common law puede responder al desafío de Jefferson sobre las generaciones, al brindar una base común, un punto de partida mínimo, a partir del cual la sociedad se puede gobernar a sí misma. Eso sería tener una Constitución viviente.

\section{Aplicabilidad del originalismo a los ordenamientos de Derecho Continental.}

Propuesta en estos términos, cabe preguntarse cuán pertinente puede ser este debate teórico del Derecho norteamericano a la cultura jurídica de los países de Derecho Continental donde, en principio, no existe un desarrollo jurídico de common law, ni tampoco las concepciones que le subyacen. Como indicamos en la introducción, los tribunales de Derecho Continental aplican de facto y de iure posiciones originalistas cuando así lo estiman, si bien no tienen el mismo marco conceptual e histórico.

La afirmación anterior exige ofrecer detenida y suficiente prueba que muestre un suceso que, a nuestro juicio, pasa básicamente inadvertido en el debate constitucional en el Derecho Continental de la actualidad, quizá más enfocado en aspectos prescriptivos como el juicio de proporcionalidad, la ponderación de derechos, la organización territorial, el tribunal constitucional frente al poder judicial o el desarrollo del contenido esencial de los derechos constitucionales (cuando en realidad sería deseable una explicitación sincera tanto de los modelos de razonamiento efectivamente empleados como una serie de propuestas que permitan ordenar los argumentos empleados). Así, hemos procedido, debido a las limitaciones de espacio, a seleccionar de forma ciertamente aleatoria sentencias de tribunales constitucionales de tradición continental, empleando sentencias de España, Alemania y Colombia.

\subsection{Sentencia del Tribunal Constitucional de España sobre el matrimonio entre personas del mismo sexo [Sentencia 198/2012].}

En este caso de control de constitucionalidad de la modificación del Código Civil español, que autorizó el matrimonio entre personas del mismo sexo, se puede decir que se presentó

37 Strauss, David, Op. cit., pp. 34-35. 
La interpretación originalista de la Constitución según

Antonin Scalia. ¿Es posible en el Derecho Continental?

el debate sobre la pertinencia de una interpretación originalista o evolutiva de la Constitución, resolviéndose en su extremo relevante, así:

"[...] es preciso determinar si la regulación contenida en la Ley 13/2005, y que da nueva redacción al párrafo segundo del art. 44 CC, hace del matrimonio una institución irreconocible y, por tanto desnaturalizada, o si el legislador ha actuado dentro del amplio margen que la Constitución le otorga. [...] Los recurrentes entienden que la ley impugnada vulnera efectivamente la garantía institucional del matrimonio, basándose en una interpretación originalista del

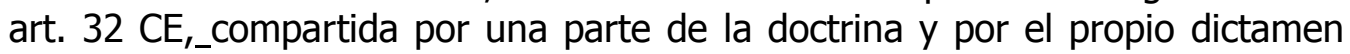
del Consejo General del Poder Judicial a que se hace referencia en los antecedentes. [...] En el año 1978, cuando se redacta el art. 32 CE era entendido mayoritariamente como matrimonio entre personas de distinto sexo, también en el seno de los debates constituyentes. Lo que el constituyente se planteaba en el año 1978 respecto del matrimonio no tenía nada que ver con la orientación sexual de los contrayentes, sino con la voluntad de desligar el matrimonio y la familia, de proclamar la igualdad de los cónyuges en el seno de la institución, y de constitucionalizar la separación y la disolución. Estas cuestiones, así como la determinación de la edad para contraer, protagonizaron casi en exclusiva los debates constituyentes sobre el actual art. $32 \mathrm{CE}$, que fuera el 27 del Anteproyecto constitucional, y que no encontró su redacción definitiva hasta la Comisión Mixta Congreso-Senado. Dicho de otro modo, en el año 1978, en que se delibera y aprueba el texto constitucional, los problemas que ocuparon al constituyente a la hora de regular la institución matrimonial fueron básicamente, tal y como se deduce de los trabajos parlamentarios, la cuestión del divorcio, la diferenciación conceptual entre matrimonio y familia, y la garantía de la igualdad entre el hombre y la mujer en el matrimonio, una igualdad que, en aquel momento, estaba todavía construyéndose. ${ }^{38}$ [...] Así, el art. 32 CE manifestaba la voluntad del constituyente por afianzar la igualdad entre el hombre y la mujer, sin resolver otras cuestiones, lo cual no significa que implícitamente acogiera el matrimonio

38 Agrega: "No puede olvidarse a este respecto que el reconocimiento normativo pleno de la capacidad de obrar a la mujer casada databa del año 1975 (Ley 14/1975, de 2 de mayo, sobre reforma de determinados artículos del Código Civil y del Código de comercio sobre la situación jurídica de la mujer casada y los derechos y deberes de los cónyuges), a pesar de lo cual los maridos eran todavía administradores de los bienes de la sociedad conyugal, salvo estipulación en contrario (artículo 59 Código Civil en la redacción vigente en 1978), se exigía su consentimiento para algunos negocios jurídicos de la esposa (por ejemplo artículo 361 Código Civil en la redacción vigente en 1978), y la madre sólo ostentaba la patria potestad en defecto del padre (artículo 154 Código Civil en la redacción vigente hasta 1981)".

FORSETI

Número 1

2015

209 
La interpretación originalista de la

Constitución según Antonin Scalia. ¿Es

posible en el Derecho Continental?

entre personas del mismo sexo, si nos limitamos a realizar una interpretación literal y sistemática, pero tampoco significa que lo excluyera. Por lo demás, desde una estricta interpretación literal, el art. 32 CE sólo identifica los titulares del derecho a contraer matrimonio, y no con quién debe contraerse aunque, hay que insistir en ello, sistemáticamente resulta claro que ello no supone en 1978 la voluntad de extender el ejercicio del derecho a las uniones homosexuales."

Como vemos en este caso, el Tribunal de España plantea directamente la cuestión y reconstruye el significado de la provisión constitucional que estaba dirigida a plantear una igualdad jurídica plena entre sexos. Siendo insuficiente para el Tribunal Constitucional español la interpretación originalista, aborda directamente la cuestión y plantea:

"Para avanzar en el razonamiento es preciso dar un paso más en la interpretación del precepto. Se hace necesario partir de un presupuesto inicial, basado en la idea, expuesta como hemos visto por el Abogado del Estado en sus alegaciones, de que la Constitución es un "árbol vivo", -en expresión de la sentencia Privy Council, Edwards c. Attorney General for Canada de 1930 retomada por la Corte Suprema de Canadá en la sentencia de 9 de diciembre de 2004 sobre el matrimonio entre personas del mismo sexo- que, a través de una interpretación evolutiva, se acomoda a las realidades de la vida moderna como medio para asegurar su propia relevancia y legitimidad, y no sólo porque se trate de un texto cuyos grandes principios son de aplicación a supuestos que sus redactores no imaginaron, sino también porque los poderes públicos, y particularmente el legislador, van actualizando esos principios paulatinamente y porque el Tribunal Constitucional, cuando controla el ajuste constitucional de esas actualizaciones, dota a las normas de un contenido que permita leer el texto constitucional a la luz de los problemas contemporáneos, y de las exigencias de la sociedad actual a que debe dar respuesta la norma fundamental del ordenamiento jurídico a riesgo, en caso contrario, de convertirse en letra muerta. Esa lectura evolutiva de la Constitución, que se proyecta en especial a la categoría de la garantía institucional, nos lleva a desarrollar la noción de cultura jurídica, que hace pensar en el Derecho como un fenómeno social vinculado a la realidad en que se desarrolla y que ya ha sido evocada en nuestra jurisprudencia previa (SSTC 17/1985, de 9 de febrero, FJ 4; 89/1993, de 12 de marzo, FJ 3; 341/1993, de 18 de noviembre, FJ 3; 29/1995, de 6 de febrero, FJ 3; y 298/2000, de 11 de diciembre, FJ 11). Pues bien, la cultura jurídica no se construye sólo desde la interpretación literal, sistemática u originalista de los textos jurídicos, sino que también contribuyen a su configuración la observación de la realidad social jurídicamente relevante, ${ }^{39}[\ldots]$ La interpretación evolutiva a que nos referimos facilita la

"A lo anterior se une la constatación de que esos tratados se van incorporando paulatina y constantemente a nuestro ordenamiento, a medida que, acordados en el seno de la sociedad internacional, la Unión Europea o el Consejo de Europa, España los ratifica, con lo cual la 
La interpretación originalista de la Constitución según

Antonin Scalia. ¿Es posible en el Derecho Continental?

respuesta a la cuestión de si el matrimonio, tal y como resulta de la regulación impugnada, sigue siendo reconocible en el contexto sociojurídico actual como tal matrimonio."

El Tribunal Constitucional español concluye entonces que, conforme a la cultura jurídica, el matrimonio sigue siendo reconocible, se respeta la garantía institucional, se trata de una opción no excluida por el constituyente y se condice con la imagen que la sociedad española tiene del matrimonio. Cabe agregar que hubo votos singulares con motivación diferente, como el del magistrado Aragón Reyes donde precisamente sobre este problema sostiene:

"La razón más importante de mi discrepancia reside en un problema de orden general, ya que no estoy de acuerdo con el modo en que la Sentencia entiende, y aplica para este caso, el concepto de interpretación evolutiva [...] En primer lugar, creo que no se subraya suficientemente, como era obligado, que el texto constitucional, en el momento de su aprobación, partía de un entendimiento del matrimonio como unión entre parejas de distinto sexo. Ese es un dato que se desprende del debate constituyente y del significado que entonces, sin duda, el matrimonio tenía en la cultura jurídica y en la conciencia social españolas y que no puede relativizarse como hace la Sentencia cuando afirma que lo más debatido entonces no era eso sino otras cosas (preferentemente la de la igualdad entre los cónyuges). [...] En ese afán, pues, de la Sentencia por reforzar (a mi juicio innecesariamente) la argumentación conducente al fallo se llega a expresar, en el fundamento jurídico, la sorprendente afirmación de que el matrimonio entre personas del mismo sexo "es una opción no excluida por el constituyente". Creo que la Constitución hay que tomársela en serio y por ello no olvidar algo que es elemental: que cuando se está en presencia de un precepto constitucional que no contiene una cláusula facultativa, sino que enuncia una garantía, como sucede con el art. 32.1 CE, y, como tal garantía, de obligatorio acatamiento, está imponiendo un deber ser y prohibiendo, obviamente, su contrario. [...] Mediante la interpretación evolutiva no puede hacérsele decir a la norma lo contrario de lo que dice, pues entonces no se interpreta la Constitución, sino que se cambia, eludiéndose el específico procedimiento de reforma que la Constitución ha previsto para ello. [...] Como bien se ha dicho en frase autorizada y respetada, "la Constitución no es una hoja en blanco que pueda reescribir el legislador a su capricho", y ha de añadirse que tampoco es una hoja en blanco que pueda

regla hermenéutica del artículo 10.2 Constitución Española lleva asociada una regla de interpretación evolutiva, que nos permitirá explicar el artículo 32 Constitución Española y el ajuste al mismo de la Ley 13/2005".

FORSETI

Número 1

2015

211 
La interpretación originalista de la

Constitución según Antonin Scalia. ¿Es

posible en el Derecho Continental?

reescribir, sin límites, su supremo intérprete. [...] Si lo fuera, sencillamente, se quebrantaría el concepto mismo de Constitución. [...] Pues bien, con esa, que llama la Sentencia "lectura evolutiva de la Constitución", sobra la rigidez constitucional, sobra la garantía que, al servicio de la rigidez, significa el procedimiento de reforma e incluso sobra la distinción entre poder constituyente y poderes constituidos. El Tribunal Constitucional, entonces, en lugar de ser, como es, un poder constituido, pasaría a ser, como ya dije, un poder constituyente permanente. [...] ha sido, más que un error, fruto de la inadvertencia, realizar estas afirmaciones sin modularlas, limitarlas, precisarlas con los necesarios matices y cautelas para que no surtan los efectos perniciosos que, dichas en términos tan generales como se dicen, podrían provocar. ${ }^{140}$

\subsection{Sentencias del Tribunal Constitucional Federal de Alemania.}

A su turno, en la Sentencia del Tribunal Constitucional Federal (BVerfGE) 1, 184 relativa al control concreto de normas, ${ }^{41}$ tenemos lo siguiente sobre la historia e intenciones legislativas:

"La historia legislativa del Artículo 100 de la Ley Fundamental tampoco brinda mayor claridad [...] El Artículo 100, párrafo 1 de la Ley Fundamental derivó del

40 Voto particular del magistrado Andrés Ollero Tassara: "La conciencia de la "historicidad" de las normas jurídicas es una exigencia fundamental en toda razonable teoría del derecho, pero no cabe confundir la historicidad del sentido de un texto jurídico con una relativización de su contenido que lo deje totalmente disponible para que el intérprete pueda atribuirle de modo voluntarista cualquier significado. [...] Aceptarlo equivaldría a admitir que no es la Constitución la que certifica y garantiza la legitimidad de las conductas sociales y políticas, sino que sería su texto el que cobraría legitimidad acomodándose a ellas". [...] 7. Afecta -a mi juicio- a la "rigidez" que en términos técnicos justifica la existencia de la Constitución, y en consecuencia la de este mismo Tribunal, la apelación reiterada de la Sentencia a una presunta presión social que obligaría a convertir su letra en prácticamente delicuescente. Se incurre así en lo que se ha llamado "falacia naturalista", o en su arcaica versión jurídica de la "fuerza normativa de lo fáctico", al pretender que determinadas pautas o conductas sociales hayan de condicionar la interpretación constitucional. Se olvida así lo que, ante la actitud dubitativa de un juez, este mismo Tribunal sentó ya con claridad en la Sentencia del Tribunal Constitucional 81/1982, de 21 de diciembre, FJ 2: "el problema no es la conformidad de la solución jurídica con las convicciones o creencias actuales, que es a lo que puede llamarse 'actualidad', sino su conformidad con la Constitución".

41 Las sentencias han sido extraídas de la traducción del alemán en: Jurisprudencia del Tribunal Constitucional Federal Alemán. Extractos de las sentencias más relevantes compiladas por Jürgen Schwabe. (Prólogo) Konrad-Adenauer-Stiftung. Traducción: Emilio Maus Ratz. Mexico DF.: Fundación Konrad Adenauer, A.C. Programa Estado de Derecho para Latinoamérica. 2009. Sentencias traducidas del Tribunal Constitucional Federal Alemán. Traducción Nicole Nucinkis y Stefanie Stöhser. Proyecto de Apoyo al Desarrollo de un Ordenamiento Jurídico Intercultural en el Marco de un Estado de Derecho Democrático. 2014. 
La interpretación originalista de la Constitución según

Antonin Scalia. ¿Es posible en el Derecho Continental?

Artículo 137, párrafo 1 del Proyecto de Herrenchiemsee (HChE), con cuyo texto coincide en gran medida. En el mismo, la palabra "ley" se refiere al sentido material, tal como se puede inferir de los comentarios al Artículo 137 del Proyecto de Herrenchiemsee (HChE: Informe pág. 94). [...] Sin embargo, ya aparece en la propuesta conjunta de los diputados Zinn, Strauss y Dehler, la cual fue la base de la deliberación del Comité de Justicia y Poder Judicial (Rechtspflegeausschuss) y que, además, coincide casi literalmente con el Proyecto de Herrenchiemsee y con la versión actual del Artículo 100 de la Ley Fundamental. Asimismo, hubo dos borradores de proyecto de los diputados Strauss y Zinn, en que utilizaron el término "disposición jurídica" en lugar de "ley". La diferencia con relación al Proyecto de Herrenchiemsee fue que ambos borradores de proyectos querían justificar la competencia jurisdiccional del Tribunal Federal Supremo (Obersten Bundesgerichts) o del Tribunal Federal de Alemania (Deutschen Bundesgerichts), en lugar del Tribunal Constitucional Federal. [...] No obstante, la propuesta conjunta de los Diputados Zinn, Strauss y Dehler preveía también un Artículo 128 B (la base del actual Artículo 93 de la Ley Fundamental), que quería unir las competencias del Tribunal Constitucional Federal y transferirle "la decisión sobre la compatibilidad formal y de contenido del derecho federal o del derecho del Estado Federado con la Ley Fundamental, o la compatibilidad del derecho del Estado Federado con otros derechos federales, a petición de un tribunal (Artículo 137, párrafo 1), del Gobierno Federal o de un Gobierno de los Estados Federados (Artículo 44)". Pero de esto tampoco se puede extraer una conclusión segura para la interpretación del Artículo 137 (Artículo 100 de la Ley Fundamental vigente), porque en la tercera Lectura de la Comisión Principal se prescindió de esta unión y se mantuvo la versión del Artículo 137 con el término "ley"."

En el caso sumamente polémico y conocido sobre la colocación de una cruz o crucifijo en las aulas de clase de una escuela pública de enseñanza obligatoria en Baviera [Resolución de la Sala Primera de 16 de mayo de 1995- 1 BvR 1087/91], donde la mayoría estableció que los crucifijos en colegios no confesionales resultaban inconstitucionales, la opinión discrepante de los magistrados Seidl y Söllner y de la magistrada Haas sostiene:

"No obstante, dentro del Estado, la Ley Fundamental asigna la competencia en materia de Derecho escolar exclusivamente a los Estados Federados (Länder). El Derecho escolar no figura en las relaciones de competencias contenidas en el artículo 73 y siguientes de la Ley Fundamental. Por tanto, la federación no tiene en esta materia ninguna competencia legislativa (art. 70 y ss. de la Ley Fundamental) ni administrativa (art. 30 de la Ley Fundamental) - a diferencia de lo que ocurría en el sistema constitucional de la República de Weimar, que, en materia escolar, conforme al artículo 10, número 2, de su Constitución

FORSETI

Número 1

2015 
La interpretación originalista de la

Constitución según Antonin Scalia. ¿Es

posible en el Derecho Continental?

confería al Reich el derecho a la legislación de principios generales. La historia del nacimiento del artículo 7 de la Ley Fundamental muestra que su espíritu era dotar de una autonomía amplia a los Estados Federados en relación con el carácter ideológico-religioso de las escuelas públicas. Aquí se impuso el principio federalista. Solicitudes que pretendían que se implantase un derecho amplio de los padres ("derecho confesional de los padres") y se garantizase en la Ley Fundamental la institución de las escuelas confesionales, fueron rechazadas ya en los debates previos sobre el artículo 7 de la Ley Fundamental. Se subrayó repetidamente que no se puede mermar la competencia de los Estados Federados en asuntos de política escolar (véase a estos efectos detalladamente BVerfGE 6, $309<356>$ con citas adicionales; además, BVerfGE 41, $29<45>$ )."

En una decisión mucho más elaborada sobre la misma, se establece Resolución de la Segunda Sala, del 17 de mayo, 1960 -2 BvL 11/59, 11/60:

"Mientras que la teoría "subjetiva" se basa en la voluntad histórica del "legislador", es decir, del redactor de la ley, cuyos motivos se encuentran en el contexto histórico, la teoría "objetiva", que goza de bastante reconocimiento en la jurisprudencia y en la doctrina, se basa en la interpretación de la ley misma, en la voluntad del legislador objetivada en la ley. "El Estado no se expresa a través de las aseveraciones personales de quienes participaron en la formación de la ley, sino en la ley misma. La voluntad del legislador va a la par de la voluntad de la ley". (Radbruch, Filosofía del derecho, 4a edición, 1950, pp. 210 y ss.) A esa finalidad de la interpretación sirven la interpretación según el tenor literal de la norma (interpretación gramatical), con base en el contexto (interpretación sistemática), con base en su finalidad (interpretación teleológica) y los estudios preparatorios de la ley y la historia de la formación de la ley (interpretación histórica). Para comprender la voluntad objetiva del legislador se permiten todos esos métodos de interpretación. Ellos no se excluyen entre sí, sino que se complementan. Esto se aplica también para el caso en que se acuda a los estudios preparatorios de la ley, en la medida en que éstos se puedan relacionar con el contenido objetivo de la ley. Claro está que "los trabajos preparatorios de una ley deben ser valorados para su interpretación con una cierta reserva, en la medida que sólo sirven de apoyo" (RGZ 128,111). De esto no se puede deducir, por tanto, que las ideas de las instancias legisladoras se puedan equiparar al contenido objetivo de la ley (por ejemplo, ya en RGZ 27, 411, además de Bayer VerfGH VGHE NF, tomo 3, II , 1950 , p. 15 [24]). La voluntad del legislador puede ser tenida en cuenta para la interpretación de la ley sólo en la medida que encuentre una expresión suficientemente determinada en la ley misma (véase, por ejemplo, BGH LM, núm. 3 sobre el §133 BGB). [...] El Tribunal Constitucional Federal manifestó en la sentencia del 21 de mayo de 1952 (BVerfGE 1, 299 [312]) que para la interpretación de una disposición legal es determinante la voluntad objetivada del legislador que se expresa en ella, en tanto que se deriva del tenor de la 
disposición legal y del contexto del sentido; así como la historia de la creación de la disposición, cuya interpretación sólo adquiere significado "cuando se confirma la exactitud de una interpretación emitida con base en los principios dados, o se presentan dudas que no puedan ser resueltas por las vías dadas". [...] Los motivos e ideas de los miembros de los cuerpos legislativos no serán, por tanto, decisivas en la medida que no encuentren expresión en la ley. Como se infiere de la historia legislativa del Art. 103, párrafo 3 de la Ley Fundamental (véase JöR 1 [1951]; 741 y ss.), por "leyes penales generales" deben entenderse las leyes criminales, no las leyes disciplinarias tradicionales [...]."

\subsection{Sentencia de la Corte de Constitucional de Colombia [C-122/11].}

En una Corte relevante en Latinoamérica como la colombiana, se aborda de esta manera la interpretación originalista:

(i) La interpretación histórica a nivel constitucional se refiere al análisis del proceso de creación de la norma constitucional para conocer la opinión general de quienes la crearon y reconstruir de esta manera la intención del constituyente. De lo que se trata es de realizar una aproximación al sentido y finalidad que los constituyentes quisieron dar al precepto e inferir de esta manera la voluntad original de los creadores de la norma.

(ii) Este tipo de interpretación ha tenido sus críticas especialmente porque, en palabras de Canosa Usera, puede "subjetivizar sin remedio la interpretación y destruir cualquier aplicación seria de los otros métodos de interpretación como el sistemático". Del mismo modo, se dice que dicho método hermenéutico es poco claro, ya que el análisis de las actas y de los debates depende de la interpretación subjetiva y "su unidad es más simbólica que real en tanto en cuanto su fragmentación en las voluntades particulares de las diferentes fuerzas políticas presentes en la elaboración de la Carta se individualizan perfectamente y provocan la casi imposibilidad de perfilar una voluntad unitaria". Igualmente para Ronald Dworkin, este tipo de interpretación resulta criticable ya que puede dar lugar a dos tipos de inferencias: la "intención semántica", es decir "lo que los redactores querían decir" y la "intención política" o "de expectativa" que consiste en determinar "las consecuencias que esperaban que tuviera lo que dijeron". 
La interpretación originalista de la

Constitución según Antonin Scalia. ¿Es

posible en el Derecho Continental?

(iii) A pesar de lo anterior, la Corte estima que en el caso concreto es importante realizar este tipo de análisis partiendo de los cargos alegados por la demandante, en especial la excepción de inconstitucionalidad de 28 de agosto de 2009 proferida por el Consejo de Estado, en donde se citan algunos de los debates que se dieron en la Constituyente, para reforzar el argumento de la inconstitucionalidad de la norma demandada. Teniendo en cuenta lo anterior, procede la Corte a analizar los antecedentes históricos del artículo 112 de la Constitución Política de Colombia para establecer la "voluntad original" de los constituyentes en la inclusión de dicho artículo.

(iv) En un primer lugar procederá la Corte a estudiar las Actas de la Asamblea Nacional Constituyente y posteriormente se analizarán algunas apreciaciones de exconstituyentes y promotores de la Constitución de 1991 en publicaciones que se realizaron con posterioridad a la aprobación de la Carta. Lo que se quiere con este análisis es determinar de forma aproximada la intención y el objetivo que tuvieron los constituyentes con la inclusión en la Constitución del artículo 112. Dicha indagación puede en efecto arrojar luces para una completa interpretación del artículo en estudio, sin embargo, se hace hincapié en que éste artículo se reformó parcialmente con el artículo $5^{\circ}$ del Acto Legislativo 1 de 2003. Teniendo en cuenta lo anterior, la Corte verificará en la última parte de este numeral si dicha modificación incide o no en la interpretación definitiva del artículo.

(v) En cuanto a los debates que se dieron en la Asamblea Nacional Constituyente verifica la Corte que la inclusión del artículo 112 de la Constitución Política de Colombia se discutió en la Comisión Primera de la Asamblea Nacional Constituyente en las sesiones del 10 de mayo al 30 de junio de 1991.

Ahora bien, ¿es una comparación válida? ¿Tiene el originalismo algún espacio en nuestros ordenamientos? Haciendo una simplificación excesiva, puede decirse tentativamente que el constitucionalismo continental europeo y latinoamericano es, conjuntamente con sus orígenes en el constitucionalismo histórico a partir de la Francia revolucionaria y sus declaraciones de derechos, un constitucionalismo de post-guerra. ${ }^{42}$ Un constitucionalismo

42 Cfr. Brewer-Carías, Allan R., Reflexiones sobre el Constitucionalismo en América, Editorial Jurídica Venezolana, Cuadernos de la Cátedra Fundacional. Dr. Charles Brewer Maucó. "Historia del Derecho de Venezuela" Universidad Católica Andrés Bello No 2, Caracas, 2001, pp. 94. Fix-Zamudio, Héctor, "El derecho internacional de los derechos humanos en las Constituciones latinoamericanas y en la Corte Interamericana de Derechos Humanos", En: Revista Latinoamericana de Derecho. Año I, núm. 1, México D.F., 2004, pp. 141-180. T. II Ferrer Mac-Gregor, Eduardo [coord.], La justicia constitucional y su internacionalización. ¿Hacia un Ius Cosntitucionale Commune en América Latina?, Instituto de Investigaciones 
generado desde la experiencia del fascismo en Europa o luego de clausurados regímenes autoritarios civiles o militares en América Latina, que constituyeron refundaciones de los Estados y dieron paso a una creciente y singular constitucionalización del Derecho. ¿Es comparable este desarrollo con el constitucionalismo norteamericano, heredero del antiguo Derecho inglés, y cuya plasmación conceptual podría encontrarse en documentos del Siglo XVIII como El Federalista o escritos semejantes que datan de época de fundación de tal Estado? Pensamos que es muy poco plausible. No puede existir un paralelismo de términos y situaciones inequiparables.

En efecto, el originalismo tiene mucho más sentido en la tradición constitucional anglosajona porque está en consonancia con una las características como modelo constitucional, como lo es su historicismo. Esta tradición historicista descansa en buena medida en dos consideraciones distintivas: 1) sitúa 'las libertades en los ciclos largos de la historia (la longue durée) sustrayéndolas por consiguiente a las peligrosas definiciones del legislador' y 2) 'las libertades negativas son desarrolladas por los tribunales en el derecho común, no por príncipes o legisladores. [Los] actos arbitrarios [de éstos] no pueden lesionar derechos históricamente adquiridos'. ${ }^{43}$ Así, el originalismo es más comprensible y tiene más sentido de ser aplicado en tradiciones donde la valoración del pasado es fundamental para la definición y concreción de los derechos. $Y$ este no es precisamente nuestro caso, donde cabe perfectamente a los fines interpretativos, de facto y de iure, prescindir del pasado histórico para definir los derechos (o al menos, no fundarse exclusivamente en él).

Este punto sobre los modelos históricos de constitucionalismo, los objetivos que perseguían y cómo lo esperaban lograr, es explicitado por Fioravanti: "En la cultura revolucionaria [norte] americana de los derechos y libertades historicismo e individualismo están fuertemente interrelacionados. Mejor dicho, se podría decir que estamos frente a una cultura que une, de manera inseparable, historicismo e individualismo. Este es el primer aspecto general que hay que poner de relieve, porque sobre esta base se hace particularmente clara y significativa la diferencia de fondo que existe entre la cultura estadounidense de los derechos y libertades y la europeo-continental, que parte de las Declaraciones de derechos de la revolución francesa. En efecto, en la cultura revolucionaria

Jurídicas de la Universidad Nacional Autónoma de México, México. Instituto Iberoamericano de Derecho Constitucional. Max Planck Institut Für Ausländisches Öffentliches Rechts Und Völkerrecht, 2010.

43 Fioravanti, Maurizio, Derechos fundamentales. Apuntes de historia de las Constituciones, Trotta. Segunda edición, Madrid, 1998, pp. 33. 
La interpretación originalista de la

Constitución según Antonin Scalia. ¿Es

posible en el Derecho Continental?

francesa de los derechos y libertades, historicismo e individualismo son absolutamente incompatibles e irreconciliables. La revolución -como ya sabemos- no puede fundar los derechos y las libertades en la historia, porque haciéndolo así se encuentra con la realidad del antiguo régimen, es decir, con el orden estamental del derecho, con el mundo de los privilegios, que intenta derribar precisamente del nuevo orden individualista fundado sobre el sujeto único de derecho. En este sentido, toda la revolución francesa se define en oposición con el antiguo régimen; y precisamente esta necesidad de ruptura hace imposible toda doctrina historicista de los derechos y las libertades". ${ }^{44}$

Por este motivo, consideramos que el debate y aplicabilidad del originalismo sólo podría ser parcialmente trasladado a nuestras sedes, donde debería de enfrentarse con las particularidades de nuestra tradición jurídica, y considerar por ejemplo los matices de la interpretación jurídica y los modelos de control de constitucionalidad. Esta limitación, que no puede ser desarrollada más detalladamente en esta oportunidad, sin embargo debería considerar que una vez que el modelo teórico kelseniano de control concentrado y sus restricciones a la interpretación han sido ampliamente superados, ${ }^{45}$ se ha dado lugar a un

44 Fioravanti, Maurizio, Derechos fundamentales. Apuntes de historia de las Constituciones, Trotta. Segunda edición, Madrid, 1998, pp. 77-79. A lo que agrega: "La revolución americana no advirtió esta necesidad porque, sencillamente, no tenía ningún "antiguo régimen" que derribar. Ciertamente, también esta revolución tenía que provocar su propia ruptura, que en este caso consistía en la separación definitiva de la madre patria, en la proclamación de independencia; pero se trataba de algo bien distinto, que no implicaba la necesidad de definirse en oposición respecto del pasado, como sucedía en la revolución francesa". Respecto a los objetivos diferentes del constitucionalismo norteamericano: "No tenía que destruir ningún orden estamental; no tenía que afirmar el dominio de la ley general y abstracta sobre las viejas fuentes del derecho; no tenía que codificar -aspecto nada irrelevante- un moderno derecho privado fundado sobre el sujeto único de derecho contra el viejo derecho común, como sucedía en Europa".

Kelsen, Hans, La garantía jurisdiccional de la Constitución, Trad, Rolando Tamayo, México, 2001, pp. 81-82. Nos permitimos citar esta breve reflexión de Kelsen sobre las implicaciones (indeseables para él) de introducir criterios sustantivos en la interpretación y control constitucional, que son precisamente los que potencian la interpretación jurídica al tratar con las dificultades del lenguaje. "El poder del tribunal sería que devendría insoportable. La concepción de la justicia de la mayoría de jueces de este tribunal podría estar en oposición completa con la concepción de la mayoría de la población, y por tanto, con la de la mayoría del Parlamento que ha votado la ley. Es obvio que la Constitución no ha querido al emplear una palabra tan imprecisa y equívoca como la de justicia o cualquier otra parecida, hace depender la suerte de toda ley votada por el Parlamento de la buena voluntad de un colegio de jueces compuesto de manera más o menos arbitraria, desde el punto de vista político, como sería el tribunal constitucional. Para evitar un semejante desplazamiento del poder que la Constitución no quiere y que, políticamente es completamente contraindicado- del Parlamento [...] la Constitución debe, sobre todo si ella crea un tribunal constitucional abstenerse de ese género de fraseología, y si quiere establecer principios relativos al contenido de las leyes, deberá formularlos de una tan precisa como sea posible." Esta

FORSETI

Número 1

2015 
La interpretación originalista de la Constitución según

Antonin Scalia. ¿Es posible en el Derecho Continental?

pluralismo interpretativo donde el desacuerdo parece ser la regla antes que la excepción. La aspiración a un Derecho formalmente perfecto, pero sin contenidos no es plausible; la interpretación va mucho más allá y nos obliga a considerar y explicitar los presupuestos en que se desenvuelve.

\section{Conclusión y reflexiones.}

En este apretado recorrido hemos apreciado cómo los tribunales emplean la interpretación originalista. En el caso del Derecho norteamericano, tanto los autores como los tribunales, entre los que destaca el juez Scalia, han desarrollado toda una doctrina o 'filosofía judicial' en torno a tal aproximación. Esto se puede explicar debido a elementos particulares, como i) la antigüedad del texto constitucional, redactado en 1787 y cuyas enmiendas son fundamentalmente del siglo XIX, que implica una constante revisión y actualización de los textos a nuevas realidades; ii) un desarrollo jurídico de common law basado en la acumulación de conocimientos y reglas, establecidas en precedentes y formas de entendimiento jurídico; iii) el rol estelar de los tribunales y el precedente en la formación histórica de su Derecho, que implica que la teoría de la interpretación sea una cuestión fundamental al momento de dar contenidos y establecer nuevas reglas; iv) el tipo propio de constitucionalismo, en el cual el elemento historicista resulta esencial para la definición de los derechos.

En nuestra opinión, como aspectos favorables de la aproximación metodológica del originalismo, podemos encontrar: i) el originalismo nos recuerda que el punto de partida del jurista debe ser los textos, el cual parece ser un punto claro y compartible para toda interpretación; ii) en un contexto de pluralismo interpretativo, el originalismo puede armonizar tensiones interpretativas al reducir en cierto grado la discrecionalidad con que el intérprete atribuye sentido a los textos; iii) si se tiene una Constitución democrática, que asegura condiciones de justicia y que por eso es una forma superior de Derecho, una aproximación originalista puede $-y$ solamente en términos de probabilidad- legitimar la actuación de los tribunales al ser un contrapeso al poder público y privado cuando éste proceda de forma incompatible con los derechos fundamentales o algún pilar del Estado de Derecho, al recurrir a un entendimiento original y más profundo de la seriedad constitucional antes que a la contingencia de legislaturas políticas y tribunales coyunturales que generan y aplican Derecho ordinario -esto, desde luego, siempre que se parta de

posición se aborda de alguna manera en la Teoría pura del Derecho, en su capítulo sobre la interpretación jurídica.

FORSETI

Número 1

2015

219 
La interpretación originalista de la

Constitución según Antonin Scalia. ¿Es

posible en el Derecho Continental?

suponer que el modelo garantiza tales derechos fundamentales y uno concuerde en que deban ser protegidos-.

Como objeciones y reservas, por otro lado, el originalismo también presentaría, a nuestro juicio, los siguientes: i) el originalismo puede desembocar en un formalismo jurídico extremo, que apostaría todo por una única solución correcta, basada en una interpretación de materiales históricos, y asumiendo con ellos los presupuestos y limitaciones que todo formalismo de 'única solución correcta' comparte; ii) el originalismo derivaría, en suma, en una posición conservadora que conduciría al riesgo de la petrificación de Derecho, teniendo claro que optar por adherirse por la rigidez o la flexibilidad de los sistemas jurídicos no sería (acaso como todo en el Derecho) una cuestión de ciencia, sino de decisiones racionalmente justificadas; iii) desde una perspectiva interpretativa, el originalismo tampoco brindaría una base completamente clara para la interpretación: se funda en el examen de documentación pasada, tendiente a descubrir o verificar el entendimiento sobre el significado de una provisión normativa, y esta evaluación podría ser en buena medida la que efectúan los historiadores. Si en el seno de los historiadores profesionales el consenso sobre las versiones de los sucesos resulta muy difícil, no vemos una razón para pensar que juristas no adiestrados en la crítica y el análisis histórico, puedan configurar un 'acuerdo historiográfico definitivo' sobre el sentido exacto de una disposición o cláusula constitucional. El consenso sobre las versiones del entendimiento histórico de una disposición normativa, sobre todo cuando contiene principio abstracto, sería entonces frágil. iv) Finalmente encontramos serios problemas metodológicos en la traducción de los textos de un tiempo al otro; la idea de que es posible primero reconstruir un significado y luego traducirlo a una época distinta, ante todo supone un elevada discrecionalidad sobre los términos de la traducción, lo que implicaría que este propósito de restringir el rol de las preferencias subjetivas de los jueces resultaría poco plausible. Precisamente el caso citado de District of Columbia v. Heller, el voto en minoría de la Corte empleó materiales textuales e históricos semejantes, para arribar a una conclusión distinta.

Los Tribunales de Derecho Continental aplican y pueden seguir aplicando, dentro de sus particularidades históricas y conceptuales, aproximaciones originalistas cuando así lo estimen. Sin embargo, se debería ser consciente que su empleo es básicamente discrecional debido a que: i) no existe impedimento teórico-metodológico para que lo empleen en su argumentación; ii) en general, el modelo de constitucionalismo no requiere examinar el pasado histórico de larga duración para definir los derechos, sino éstos, más bien, se van llenando de contenido a través de la legislación de desarrollo de los mismos y sobre todo de la doctrina que acumulan los tribunales en sus decisiones respecto a los mismos, incluso en control de la legislación, y que sí establecen un campo semántico y un corpus de contenidos sustantivos sobre los alcances de cada derecho o institución 
constitucional; iii) los Tribunales de Derecho Continental pueden acudir al originalismo como un recurso o argumento interpretativo adicional cuando una interpretación literal, convencional o sistemática parezca insuficiente para responder a las preguntas jurídicas planteadas. Ahora bien, cuándo y en qué términos acudir o no al originalismo, a nuestro juicio, resulta por principio, incontrolable.

A modo de propuesta preliminar, que debería ser debidamente desarrollada, el originalismo puede ser superado al acudir a métodos interpretativos distintos cuando su aplicación no parezca justificada por razones de consistencia y acierto sino que conduzca a un vaciamiento de contenidos, principios o legitimidad de la justicia constitucional. El estándar interpretativo abierto puede ser legítimo siempre que no se vea una manifiesta transgresión de la rigidez constitucional, sino como un desarrollo y evolución razonablemente justificados del Derecho que pueda armonizar elementos en tensión del ordenamiento jurídico. Este pluralismo interpretativo dentro de márgenes de plausibilidad, que resulta inescapable en todo conocimiento jurídico, sería consistente con lo establecido por la metodología jurídica avanzada sobre las condiciones de posibilidad de nuestro conocimiento como juristas. 